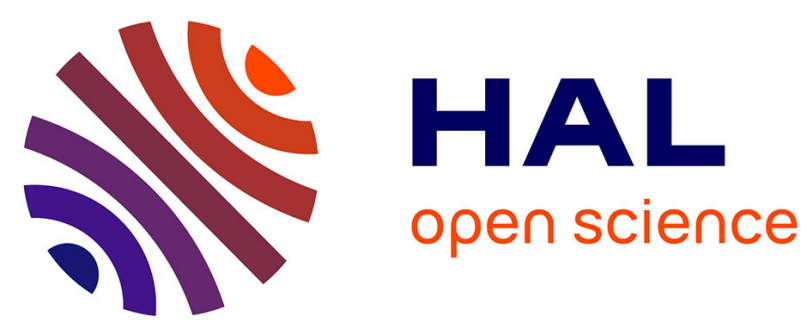

\title{
Tin dioxide nanoparticles as catalyst precursors for plasma-assisted vapor-liquid--solid growth of silicon nanowires with well-controlled density
}

Letian Dai, Isabelle Maurin, Martin Foldyna, José Alvarez, Weixi Wang, Hamza Mohsin, Wanghua Chen, Jean-Paul Kleider, Jean-Luc Maurice, Thierry Gacoin, et al.

\section{To cite this version:}

Letian Dai, Isabelle Maurin, Martin Foldyna, José Alvarez, Weixi Wang, et al.. Tin dioxide nanoparticles as catalyst precursors for plasma-assisted vapor-liquid-solid growth of silicon nanowires with well-controlled density. Nanotechnology, 2018, 29 (43), 10.1088/1361-6528/aad7db . hal-01908717

\section{HAL Id: hal-01908717 https://hal.science/hal-01908717}

Submitted on 11 Mar 2020

HAL is a multi-disciplinary open access archive for the deposit and dissemination of scientific research documents, whether they are published or not. The documents may come from teaching and research institutions in France or abroad, or from public or private research centers.
L'archive ouverte pluridisciplinaire HAL, est destinée au dépôt et à la diffusion de documents scientifiques de niveau recherche, publiés ou non, émanant des établissements d'enseignement et de recherche français ou étrangers, des laboratoires publics ou privés. 
ACCEPTED MANUSCRIPT

\section{Tin dioxide nanoparticles as catalyst precursors for plasma-assisted vapor-liquid-solid growth of silicon nanowires with well-controlled density}

To cite this article before publication: Letian Dai et al 2018 Nanotechnology in press https://doi.org/10.1088/1361-6528/aad7db

\section{Manuscript version: Accepted Manuscript}

Accepted Manuscript is "the version of the article accepted for publication including all changes made as a result of the peer review process, and which may also include the addition to the article by IOP Publishing of a header, an article ID, a cover sheet and/or an 'Accepted Manuscript' watermark, but excluding any other editing, typesetting or other changes made by IOP Publishing and/or its licensors"

This Accepted Manuscript is @ 2018 IOP Publishing Ltd.

During the embargo period (the 12 month period from the publication of the Version of Record of this article), the Accepted Manuscript is fully protected by copyright and cannot be reused or reposted elsewhere.

As the Version of Record of this article is going to be / has been published on a subscription basis, this Accepted Manuscript is available for reuse under a CC BY-NC-ND 3.0 licence after the 12 month embargo period.

After the embargo period, everyone is permitted to use copy and redistribute this article for non-commercial purposes only, provided that they adhere to all the terms of the licence https://creativecommons.org/licences/by-nc-nd/3.0

Although reasonable endeavours have been taken to obtain all necessary permissions from third parties to include their copyrighted content within this article, their full citation and copyright line may not be present in this Accepted Manuscript version. Before using any content from this article, please refer to the Version of Record on IOPscience once published for full citation and copyright details, as permissions will likely be required. All third party content is fully copyright protected, unless specifically stated otherwise in the figure caption in the Version of Record.

View the article online for updates and enhancements. 


\title{
Tin dioxide nanoparticles as catalyst precursors for plasma- assisted vapor-liquid-solid growth of silicon nanowires with well-controlled density
}

\author{
Letian Dai ${ }^{1,2,3}$, Isabelle Maurin ${ }^{3, *}$, Martin Foldyna ${ }^{2, *}$, José Alvarez ${ }^{1, *}$, Weixi \\ Wang $^{2}$, Hamza Mohsin ${ }^{2,3}$, Wanghua Chen ${ }^{2}$, Jean-Paul Kleider ${ }^{1}$, Jean-Luc \\ Maurice $^{2}$, Thierry Gacoin ${ }^{3}$ and Pere Roca i Cabarrocas ${ }^{2}$ \\ ${ }^{1}$ GeePs, CNRS, CentraleSupelec, Université Paris-Sud, Université Paris-Saclay, \\ Sorbonne Université-UPMC Université Paris 06, 91192 Gif-sur-Yvette Cedex, France \\ ${ }^{2}$ LPICM, CNRS, Ecole Polytechnique, Université Paris-Saclay, 91128 Palaiseau,
} France

${ }^{3}$ Physique de la Matière Condênsée, CNRS, Ecole Polytechnique, Université ParisSaclay, 91128 Palaiseau, France

*E-mail : isabelle.maurin@polytechnique.edu;

martin.foldyna@polytechnique.edu; jose.alvarez@geeps.centralesupelec.fr.

ABSTRACT: The fabrication of arrays of silicon nanowires ( $\mathrm{Si}$ NWs) with well-defined surface coverage using the vapor-liquid-solid (VLS) process requires a good control of the density and size distribution for the metal catalyst. We report on a cost-effective bottom-up 
approach to produce Si NWs by a low-temperature deposition technology using plasmaenhanced chemical vapor deposition (PECVD) and tin dioxide $\left(\mathrm{SnO}_{2}\right)$ nanoparticles as the source of tin catalyst. This strategy offers a straightforward method to select specific particle sizes by conventional colloidal techniques, and to tune the surface coverage using a polyelectrolyte layer to efficiently immobilize the particles on the substrate by electrostatic grafting. After a further step of reduction into tin metal droplets using hydrogen plasma treatment, the catalyst particles are used for the growth of $\mathrm{Si}$ NWs. This approach allows to produce controlled Si NWs arrays which can be used as a template for radial-junction thin film solar cells. 


\section{INTRODUCTION}

Solar energy is one important renewable energy source for the future. Photovoltaic (PV) solar cells provide a seducing shortcut to directly convert sunlight into a very convenient form of energy which is electricity. In 2005, Kayes et al. fabricated radial junction (RJ) solar cells based on coaxial silicon nanowires (Si NWs) [1]. This new generation of cost-effective solar cells has been further improved and has already resulted in an efficiency of $9.2 \%$ with a single p-i-n RJ (p-core Si NW) and $100 \mathrm{~nm}$ thick absorber layer [2]. The radial junction architecture benefits from strong light trapping and efficient carrier collection [3], leading to an increase in overall efficiency of the RJ solar cells. Optical modeling indicates that the density of Si NWs should be of the order of $10^{8} \mathrm{NW} / \mathrm{cm}^{2}$ for optimized performance [4]. Simulations have also shown that the n-i-p structure (with n-core Si NW) should give higher power conversion efficiency (as high as $12 \%$ ) [5] than the p-i-n configuration. Moreover, tandem structures result in a larger absorption spectrum and higher open circuit voltage $\left(\mathrm{V}_{\text {oc }}\right)$ that have a potential for improving further the performance of RJ solar cells [6]. At the present stage, optical design is mainly based on the control of the density, size distribution, and morphology of the Si NWs forest. In addition, the PV functionality relies strongly on the uniformity and quality of intrinsic and doped layers around the Si NW cores, which enforces a sufficient space between NWs for the subsequent formation of radial junctions.

Vapor-liquid-solid (VLS) growth is a bottom-up technique for the fabrication of Si NWs [7]. This process involves the use of a metal catalyst that acts as a seed for the growth of NWs, which is usually achieved by chemical vapor deposition (CVD), but it can also be carried out by plasma-enhanced CVD (PECVD) at lower temperatures. Gold [8], aluminum [9], bismuth [10], indium [11], and tin $[11,12]$ have been employed as catalysts for the growth of Si NWs in the past. Sn is a good candidate because of its low melting temperature $\left(231.9^{\circ} \mathrm{C}\right)$, low cost, abundance, and ability to prevent the formation of deep defect levels in the silicon lattice. Moreover, it was recently shown that it is possible to catalyze Si NWs in the metastable hexagonal-diamond structure [13], the calculated band structure of which presents several interesting features, including a direct band gap in thin NWs [14]. 
First attempts to grow $\mathrm{Si}$ NWs through the surface reduction of $\mathrm{SnO}_{2}$ or ITO coatings by $\mathrm{H}_{2}$ plasma treatment have already been reported [12]. Better defined catalyst distributions were achieved using thermal evaporation of $\mathrm{Sn}$ in high vacuum, which led to the formation of a thin film of $\mathrm{Sn}$ on the substrate $[12,15,16]$. Upon dewetting, this evaporated Sn layer forms isolated droplets. In order to have forests of Si NWs with uniform diameter and length, a narrow size distribution of the tin catalyst is necessary, with mean particle sizes around $50 \mathrm{~nm}$. As already mentioned, the final NW density has a large impact on light absorption and therefore on the short circuit current of radial junction solar cells, so that a well-defined density of Sn droplets is also required to optimize NW based devices. The standard approach for controlling the Si NWs density is to control the density of catalyst particles by varying the thickness of the thermally evaporated tin film $[12,15,16]$. However, it is not easy to independently tune the size of the Sn droplets and their density by the thermal evaporation of Sn or surface reduction of $\mathrm{SnO}_{2}$ coatings [17]. For instance, large spacing between Sn droplets of around 1 $\mu \mathrm{m}$ with 10 to $100 \mathrm{~nm}$ particle sizes cannot be achieved. An efficient alternative is to use electron beam lithography to obtain well-defined catalyst size and specific localization, but such process is obviously expensive and hardly scalable.

The present work investigates an alternative method for the control of the catalyst distribution using colloidal solutions of $\mathrm{SnO}_{2}$ nanoparticles (NPs) deposited onto the surface by wet-chemical routes. In particular, we aim at NPs' density smaller than $10^{8} \mathrm{~cm}^{-2}$, which cannot be obtained with evaporated $\mathrm{Sn}$ for future tandem architecture. Solutions of $\mathrm{SnO}_{2} \mathrm{NPs}$ can be obtained by direct synthesis using conventional colloidal chemistry $[18,19]$. Herein, we focus on a very simple and scalable approach based on the dispersion of particles extracted from commercially available $\mathrm{SnO}_{2}$ nanocrystalline powders. The main challenges are related to the size selection (targeted to be around $50 \mathrm{~nm}$ with low size polydispersity) and appropriate dispersion of particles extracted from the initial powder to form colloids that are stable over time. Starting from these colloidal suspensions, different methods can be used for their deposition on a substrate such as spin or dip-coating, but electrostatic grafting was preferred considering the ability to have uniform distributions on the surface and a simple 
control of the particles density [20,21]. At first, a monolayer of a charged polymer is deposited on the substrate, with an electric charge opposite to that of the $\mathrm{SnO}_{2} \mathrm{NPs}$. In a second step, the substrate is immersed for a given duration in the colloidal solution, and then rinsed extensively to remove nongrafted particles. With the assistance of the hydrogen plasma, the reduction of $\mathrm{SnO}_{2}$ into $\mathrm{Sn}$ can be realized at a relatively low temperature $\left(\sim 250^{\circ} \mathrm{C}\right)$ as compared to thermal treatment in a hydrogen atmosphere for which the onset of reduction is above $490{ }^{\circ} \mathrm{C}$ [22]. In this work, we studied plasmaassisted reduction from $\mathrm{SnO}_{2}$ to metallic $\mathrm{Sn}$ and its impact on the final distribution of the Sn catalyst. Then, the density of Si NWs was eventually investigated in relation to the Sn droplets with controlled distribution.

\section{EXPERIMENTAL SECTION}

Tin dioxide NP powder with a purity of $99.5 \%$ and $55 \mathrm{~nm}$ nominal particle size was purchased from Goodfellow. The as-received powder mostly contains micrometer-sized aggregates and requires a preliminary step of ball milling before dispersion in alkaline aqueous solution. The tin dioxide powder (4.5 g) was mixed with $14 \mathrm{~mL}$ diethylene glycol (DEG, $\geq 99.0 \%$, Sigma-Aldrich) and placed with 150 zirconia balls of $5 \mathrm{~mm}$-diameter in a $40 \mathrm{~mL} \mathrm{ZrO}_{2}$ bowl. This mixture was ball-milled using a FRITSCH Pulverisette 6 for 10 cycles of $15 \mathrm{~min}$ at $600 \mathrm{rpm}$ with a rest time of 6 min between each cycle to minimize heating. The concentrated suspension was then dropwise added into a solution of tetramethylammonium hydroxide (TMAOH) obtained from a $25 \mathrm{wt} \% \mathrm{TMAOH}$ solution (SigmaAldrich) after dilution with ultrapure water to tune the $\mathrm{pH}$ value from 9 to 13 . A volume of $1 \mathrm{~mL}$ of $\mathrm{SnO}_{2} / \mathrm{DEG}$ mixture diluted in $99 \mathrm{~mL}$ of $\mathrm{TMAOH}$ solution corresponds to a concentration of about $3.2 \mathrm{~g} / \mathrm{L}$. Particle size selection was achieved by differential centrifugation (Fisher Bioblock Scientific Sigma 3K10) with accelerations ranging from 1,000 to $11,000 \mathrm{~g}$ (gravity) for $5 \mathrm{~min}$. After elimination of the precipitate, nanoparticles were recovered from the supernatant. Their immobilization was achieved onto silicon wafers after a preliminary cleaning. This step consists of immersing the substrate in $3 \%$ TFD4 solution in water for 20 min followed by extensive rinsing with water, drying using a $\mathrm{N}_{2}$ 
gas stream and UV/ozone treatment at $50{ }^{\circ} \mathrm{C}$ for $15 \mathrm{~min}$ to remove residual organic contaminations. Poly(diallyldimethylammonium) chloride (PDDAc, molecular weight 100,000-200,000) was purchased from Aldrich (20 wt $\%$ solution of PDDAc in water). The cleaned silicon wafers were immersed in a diluted $0.2 \mathrm{wt} \%$ PDDAc aqueous solution for $10 \mathrm{~min}$, then thoroughly rinsed with deionized water and blown dried under a stream of nitrogen. The Si wafer surface was thus functionalized by a $\mathrm{PDDA}^{+}, \mathrm{Cl}^{-}$monolayer. $1 \mathrm{~mL}$ of $\mathrm{SnO}_{2}$ colloidal suspension was then deposited on the substrate and left for $5 \mathrm{~min}$, then rinsed with deionized water and dried by nitrogen gas flow. The resulting samples were heated up to $450^{\circ} \mathrm{C}$ in the air for 1.5 hours (with $5{ }^{\circ} \mathrm{C} / \mathrm{min}$ ramping) to remove the PDDA overlay.

Two different procedures were carried out to reduce $\mathrm{SnO}_{2}$ to metallic Sn: (i) hydrogen plasma treatment in a plasma reactor using a flow rate of $100 \mathrm{sccm}$ (standard cubic centimeters per minute) $\mathrm{H}_{2}$ under 0.8 mbar pressure at $400{ }^{\circ} \mathrm{C}$ for $10 \mathrm{~min}$ and a $\mathrm{RF}$ power of $10 \mathrm{Watt}$; or (ii) thermal treatment under reductive atmosphere $\left(10 \% \mathrm{H}_{2}\right.$ and $\left.90 \% \mathrm{Ar}\right)$ at $700{ }^{\circ} \mathrm{C}$ at a pressure of 1 bar for $30 \mathrm{~min}$. After these reduction steps, the samples were taken out into the air. Some reduced Sn droplets were recovered for analysis by transmission electron microscopy (TEM). These particles were transferred to a TEM grid by scratching with a tweezer and immersing in a little amount of isopropanol.

The Si NWs were grown on plasma-treated substrates previously characterized by scanning electron microscopy (SEM). Because of oxidation in air, growth involved several steps: $\mathrm{H}_{2}$ plasma treatment at $400{ }^{\circ} \mathrm{C}$ for $2 \mathrm{~min}, \mathrm{RF}$ power of 10 Watt, followed by stopping the plasma, introducing 1 sccm silane $\left(\mathrm{SiH}_{4}\right)$ at the same temperature, waiting around $5 \mathrm{~min}$ and starting again the plasma with a RF power of 2 Watt for 60 min. The corresponding deposition rate of a-Si:H on reference Corning glass is $9.3 \AA / \mathrm{min}$. Some Si NWs were transferred to TEM grids using the procedure described above for the tin particles.

Size, zeta potential, and dispersion state of the colloids, were characterized by Dynamic Light Scattering (DLS) using a Malvern Nano ZS zetasizer. A PANalytical X-Pert diffractometer equipped with $\mathrm{Cu} / \mathrm{K \alpha}$ radiation was used to characterize the commercial $\mathrm{SnO}_{2}$ powder. Microstructural 
characterizations were carried out by SEM and TEM. We used a Hitachi S4800 FEG-SEM operating at $10 \mathrm{kV}$. Size distribution, surface density and nearest neighbor distances of $\mathrm{SnO}_{2} \mathrm{NPs}$ were determined by analysis of the SEM images using the ImageJ software [23]. Statistics were carried out over more than 1000 particles. TEM imaging was carried out with a FEI Titan G2 ETEM (NanoMAX) operating at $300 \mathrm{kV}$ and equipped with an objective lens Cs corrector, a High Angle Annular Dark Field (HAADF) Scanning Transmission Electron Microscopy (STEM) module and an energydispersive X-ray spectroscopy (EDS) detector.

\section{RESULTS AND DISCUSSION}

Preparation of $\mathrm{SnO}_{2}$ dispersions and deposition onto silicon substrates. The commercial $\mathrm{SnO}_{2}$ cassiterite nanopowder consists of tens of micrometer/aggregates made of $55 \mathrm{~nm}$ primary nanoparticles (see Figure S1 in supplementary information). The powder was first dispersed in DEG and disaggregated by ball milling [24]. DEG was chosen because this solvent is polar and helps the dispersion by interacting with the surface of the NPs. Aliquots of this grounded suspension were then added to a TMAOH aqueous solution in order to ensure electrostatic repulsions between particles, as the point of zero charge (PZC) of $\mathrm{SnO}_{2}$ cassiterite is 3.5-4.5 [25,26]. A colloidal solution with a particle concentration of $\sim 3.2 \mathrm{~g} / \mathrm{L}$ was prepared, starting from the $320 \mathrm{~g} / \mathrm{L}$ grounded powder in DEG (hereafter named as 100-time diluted solution). Figure 1(a) shows the zeta potential of $\mathrm{SnO}_{2} \mathrm{NPs}$ in TMAOH solutions of $\mathrm{pH}$ values ranging between 9 and 13, after a preliminary centrifugation at $3,500 \mathrm{~g}$ to remove residual aggregates. The negative sign of the zeta potential indicates negatively charged $\mathrm{SnO}_{2}$ particles. Usually, an absolute value over $30 \mathrm{mV}$ is considered as a good indication of colloidal stability. For the 100-time diluted solution, we thus selected a $\mathrm{pH}$ of 12 as it yields the highest zeta potential absolute value. Such a suspension is stable over a week. 

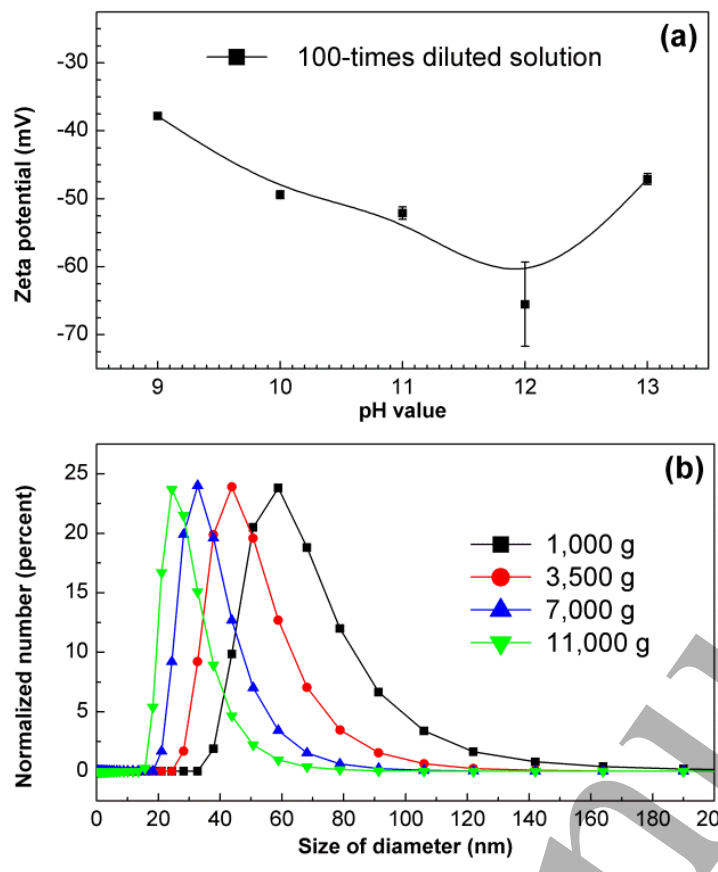

(b)

Figure 1. (a) Zeta potential of $\mathrm{SnO}_{2} \mathrm{NPs}$ after dilution $(1 / 100 \mathrm{v} / \mathrm{v})$ in TMAOH solutions of different $\mathrm{pH}$ values and centrifugation at 3,500 $\mathrm{g}$ for $5 \mathrm{~min}$; The solid line is a guide to the eye (b) Size distribution of $\mathrm{SnO}_{2} \mathrm{NPs}_{\text {in }}$ the supernatant for $\mathrm{pH} 12$ TMAOH solutions after centrifugation at 1,000, 3,500, 7,000 and 11,000 g for $5 \mathrm{~min}$.

The next step is a centrifugation to select individual particles and decrease the width of the size distribution. Indeed, high acceleration makes sedimentation of particles much faster with a sizedependent rate, so that big particles are recovered as a precipitate and the smallest ones remain in the supernatant. The diameter of these latter particles is directly dependent on the centrifugation speed as illustrated in Figure 1(b). This plot shows the size distribution of $\mathrm{SnO}_{2} \mathrm{NPs}$ in the supernatant after 5 min centrifugation at accelerations of $1,000,3,500,7,000$ and $11,000 \mathrm{~g}$, with a wider distribution and larger mean size observed for the solution centrifuged at $1,000 \mathrm{~g}$ as compared to the other cases.

At this stage, the $\mathrm{SnO}_{2}$ NPs were deposited on silicon substrates. First, a thin layer of PDDAc was adsorbed onto the surface to graft the $\mathrm{SnO}_{2} \mathrm{NPs}$ and avoid their aggregation upon evaporation of the solvent. Then, this functionalized surface was immersed in the colloidal solution of size selected $\mathrm{SnO}_{2}$ particles. The SEM images of Figures 2(a) to 2(d) are representative of the surface coverage after 5 min immersion using the $\mathrm{SnO}_{2}$ suspensions of Figure 1(b), i.e. centrifuged at increasing acceleration. Statistical analyses of the particle sizes are in fair agreement with the DLS results: both the mean 
value and the width of the size distribution decrease with the increase of the centrifugation speed, as shown in Figure 2(e). However, the mean particle size is systematically smaller than the one determined by DLS in the colloidal solution, as clearly observed after centrifugation at $1,000 \mathrm{~g}$. To some extent, this could account for a higher adsorption rate of small particles (diameter around $30 \mathrm{~nm}$ ) with respect to big ones. The area density of $\mathrm{SnO}_{2}$ nanoparticles also decreases from $1.3 \times 10^{9} \mathrm{NP} / \mathrm{cm}^{-2}$ to $1.4 \times 10^{8} \mathrm{NP} / \mathrm{cm}^{-2}$ by increasing the centrifugation speed from 1,000 to $11,000 \mathrm{~g}$. It results in an increase of the mean value of nearest neighbor distances, which are equal to $\sim 150,200,270$ and $420 \mathrm{~nm}$ in Figures 2(a) to 2(d), respectively. These SEM images also show that at 1,000 $\mathrm{g}$ and to a lesser extent at 3,500 g, some particles are still in the form of aggregates while at higher centrifugation speed they can be considered as individual ones.

(a)
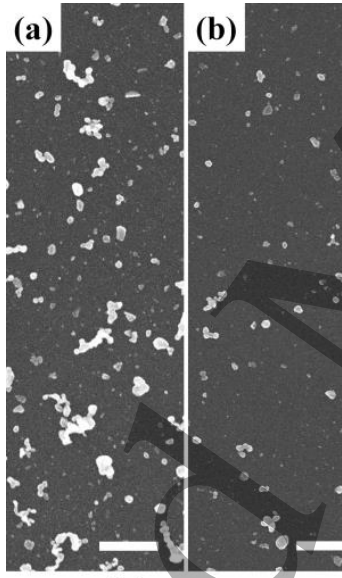

(c)

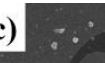

(d)

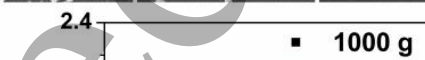

- $3500 \mathrm{~g}$

- $7000 \mathrm{~g}$

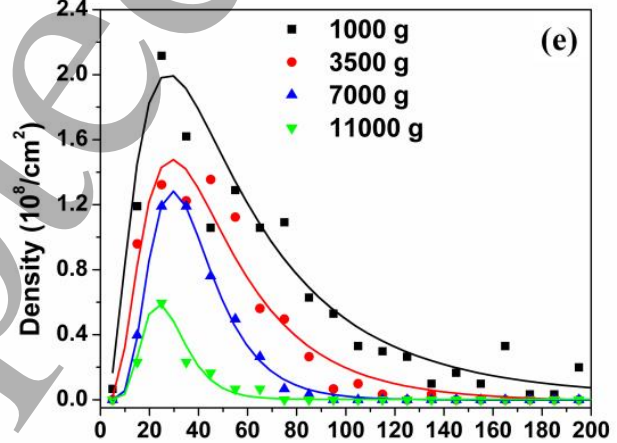

Diameter of nanoparticle $(\mathrm{nm})$

Figure 2. (a to d) SEM images representative of the distribution of $\mathrm{SnO}_{2} \mathrm{NPs}$ after 5 min immersion of the Si/PDDAc substrate in colloidal solutions centrifuged at: (a) 1,000, (b) 3,500, (c) 7,000 and (d) 11,000 g. Scale bar $500 \mathrm{~nm}$. (e) Size distribution determined from selected SEM images with $10 \mathrm{~nm}$ bin size. Solid lines correspond to fits by lognormal functions. 
The surface coverage decreases with the increase of the centrifugation speed, reflecting a decreâsed concentration of $\mathrm{SnO}_{2} \mathrm{NPs}$ in the TMAOH solutions. Indeed, if we compare the NP density for $100-$ time dilution $(\sim 3.2 \mathrm{~g} / \mathrm{L}$ solution $)$ vs. 1000-time dilution $(\sim 0.3 \mathrm{~g} / \mathrm{L})$ of the original $\mathrm{DEG} / \mathrm{SnO}_{2}$ mixture, we find a similar decrease of the surface coverage. Figures 3(a), 3(b) and 3(c) compare qualitatively and quantitatively the as-obtained densities for colloidal solutions that were both first centrifuged at $3,500 \mathrm{~g}$ for $5 \mathrm{~min}$. This density of $\mathrm{SnO}_{2} \mathrm{NPs}$ is almost four times smaller in the case of the 1000-time dilution, with a mean nearest neighbor distance that increases from $200 \mathrm{~nm}$ to $370 \mathrm{~nm}$ with respect to the 100-time diluted solution. Moreover, the size distributions are nearly the same for the two dilutions. It means that the size polydispersity is mainly dependent on the acceleration of centrifugation. However, it is worth mentioning that the dilution should be performed before the size selective centrifugation steps. Otherwise, we found rather surprisingly that particles on the substrate are much more aggregated, whereas the distributions in the solution are comparable from DLS data. The reason for this difference remains unclear yet.

The present colloidal approach to control the density and the size of the catalyst NPs appears more accurate than thermal evaporation because those two quantities can be tuned independently. Moreover, low densities of $\mathrm{SnO}_{2} \mathrm{NPs}$ can be obtained in a straightforward and repeatable way. 

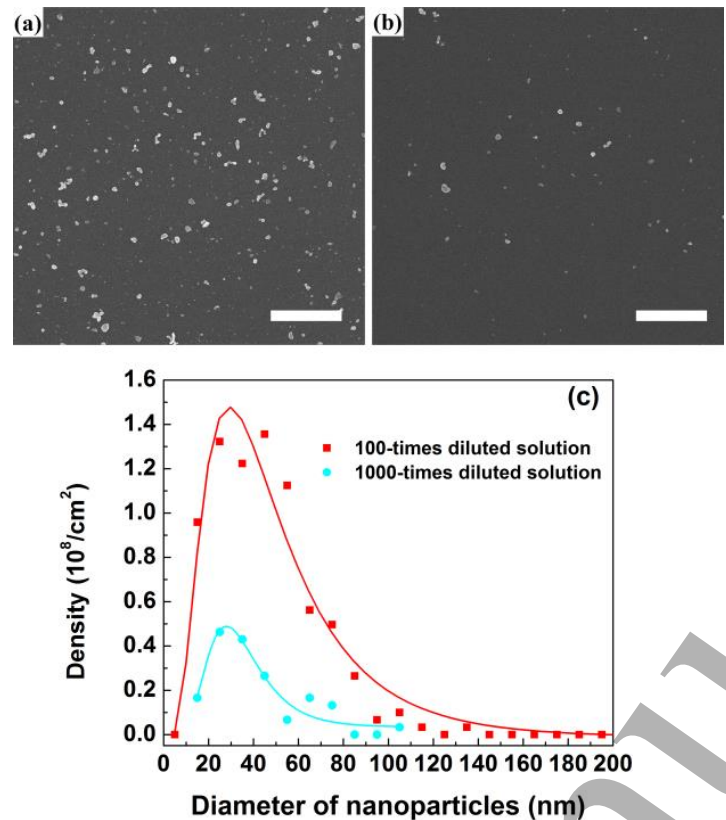

Figure 3. SEM images of $\mathrm{SnO}_{2} \mathrm{NPs}$ grafted onto functionalized Si/PDDAc surfaces using 1/100 v/v (a) and 1/1000 v/v (b) diluted solutions of the initial $\mathrm{DEG} / \mathrm{SnO}_{2} \mathrm{NP}$ mixture and the same immersion time of $5 \mathrm{~min}$. A preliminary centrifugation at 3,500 g for $5 \mathrm{~min}$ was performed before grafting. Scale bars: $1 \mu \mathrm{m}$ in (a) and (b). (c) Size distribution of the $\mathrm{SnO}_{2} \mathrm{NPs}_{\mathrm{s}}$ for dilutions (a) and (b), with $20 \mathrm{~nm}$ bin size. Solid lines are fits by lognormal functions.

Hydrogen reduction of $\mathrm{SnO}_{2}$ NPs. We compared two reduction paths to turn the $\mathrm{SnO}_{2}$ particles into metallic Sn: hydrogen plasma treatment and thermal reduction under $\mathrm{H}_{2} / \mathrm{Ar}$ atmosphere. Figures 4 and $\mathrm{S} 2$ in the ESI show the effect of the above-mentioned treatments on $\mathrm{SnO}_{2}$ NPs characterized by SEM. In the case of the hydrogen plasma treatment at $400{ }^{\circ} \mathrm{C}$, the morphology of the NPs is strongly modified from slightly faceted to spherical likely because of a partial or complete transformation in a melt state $\left(\mathrm{Sn}: T_{\mathrm{m}} \neq 231.9^{\circ} \mathrm{C}\right.$ ). In addition, for well separated particles such as those targeted in the present work, this treatment does not lead to significant tin diffusion or droplet coalescence. Indeed, the comparison of Figures 4(c) and 4(d) or 4(e) and 4(f) shows similar distribution and localization of the catalyst particles before and after the plasma treatment. We do not expect a substantial change in the particle size upon reduction, except when coalescence occurs, because of the similar density of $\mathrm{SnO}_{2}$ cassiterite and $\beta-\mathrm{Sn}\left(\sim 7.0\right.$ and $7.3 \mathrm{~g} / \mathrm{cm}^{3}$, respectively). On the other hand, the thermal treatment 
at $700{ }^{\circ} \mathrm{C}$ under $\mathrm{H}_{2} / \mathrm{Ar}$ atmosphere did not modify the morphology of the catalyst particles. It only led to the formation of tiny dots of diameters of less than $5 \mathrm{~nm}$ at the particle surface, see Figures S2(a) and S2(b) in supplementary information.

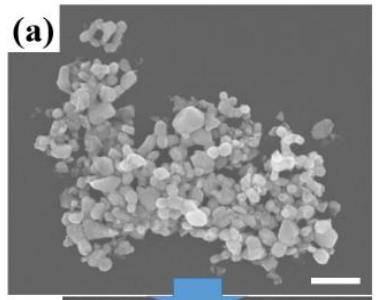

(b)

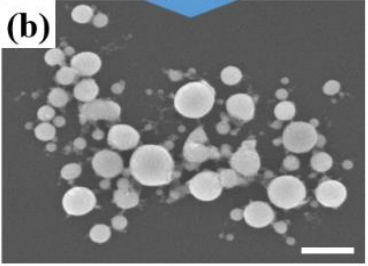

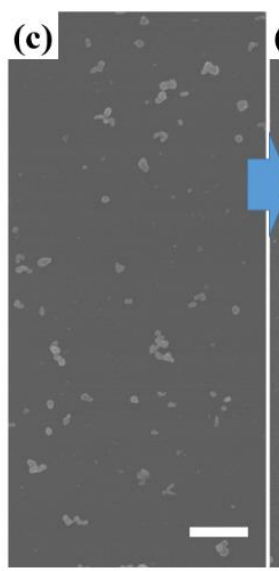
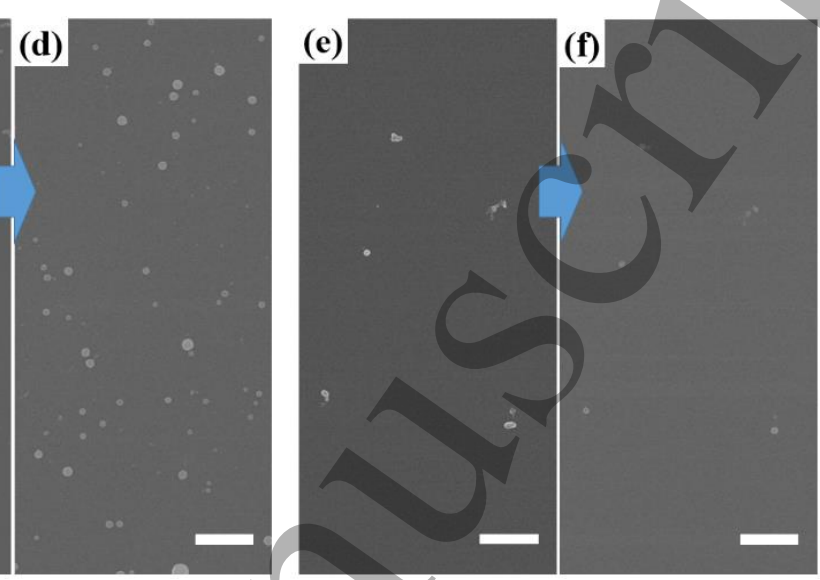

Figure 4. Top view SEM image of the same aggregate of $\mathrm{SnO}_{2}$ particles (a) before and (b) after hydrogen plasma treatment at $400{ }^{\circ} \mathrm{C} . \mathrm{SnO}_{2} \mathrm{NPs}$ deposited from the 100-time diluted solution after centrifugation at 3,500 $\mathrm{g}$ for 5 min with a rather large density $\left(\sim 9 \times 10^{8} \mathrm{NP} / \mathrm{cm}^{2}\right)$ (c) before and (d) after plasma reduction. $\mathrm{SnO}_{2} \mathrm{NPs}$ with lower density $\left(\sim 8 \times 10^{7} \mathrm{NP} / \mathrm{cm}^{2}\right)$ obtained from the 1000-time diluted solution after centrifugation at $11,000 \mathrm{~g}$ for $5 \mathrm{~min}$ (e) before and (f) after plasma reduction. Scale bars: $200 \mathrm{~nm}(\mathrm{a}-\mathrm{b}), 500 \mathrm{~nm}(\mathrm{c}-\mathrm{f})$, respectively.

To study this reduction step more quantitatively, we have performed chemical mapping by STEMEDS on catalyst particles transferred on a TEM grid after the $\mathrm{H}_{2}$ plasma treatment and one month storage in ambient air. The comparison is made with pristine $\mathrm{SnO}_{2}$ particles. Figure 5 summarizes the results of EDS elemental analysis. Figure 5(b) shows the intensity of oxygen $\mathrm{K}_{\alpha}$ and tin $\mathrm{L}_{\alpha}$ peaks, corresponding to the $\mathrm{SnO}_{2} \mathrm{NP}$ shown in Figure 5(a). The oxygen is present at the same concentration everywhere in the particle. Figure 5(d) shows the intensity of oxygen $\mathrm{K}_{\alpha}$ and tin $\mathrm{L}_{\alpha}$ peaks in two selected parts of the $\mathrm{H}_{2}$ plasma-treated NP shown in Figure 5(c): the peak intensity ratio corresponds to the $\mathrm{SnO}_{2}$ reference at the NP surface, but there is a much smaller oxygen signal in the center. Figure 5(e) shows the chemical map corresponding to the high-angle annular dark field (HAADF) image of Figure 5(c) and 5(f) displays the quantitative concentrations deduced from the two spectra in Figure 
5(d). It is clear that the oxygen is mostly concentrated in the shell part. The atomic ratio between $\mathrm{Sn}$ and $\mathrm{O}$ is $\sim 8: 1$ at the central part and $\sim 1: 1.8$ in the shell part. The oxygen fraction of $11 \%$ in the central zone is mostly because we are also probing part of the outer shell. These data indicate that the central region of the $\mathrm{SnO}_{2}$ NPs has been fully reduced by hydrogen plasma treatment but that the outside shell was re-oxidized after exposition to the air. As reported by other authors, hydrogen plasma reduction is thus much more efficient than the thermal reduction in hydrogen $[22,27,28]$. Moreover, the growth of Si NWs can be achieved in the same chamber just after plasma treatment, allowing for a single pumpdown process.
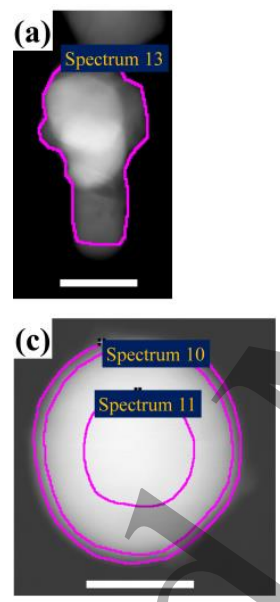

(e)

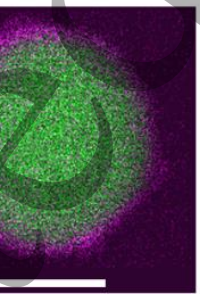

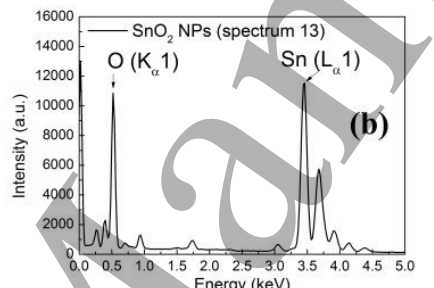
Energy $(\mathrm{keV})$ ${ }_{140000}^{1600}-$ Shell part (spectrum 10)
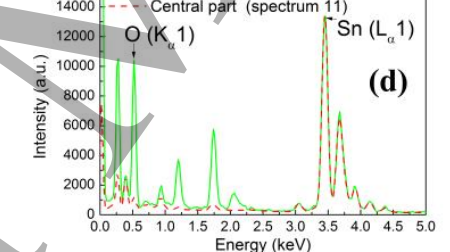

(f) Quantitative results

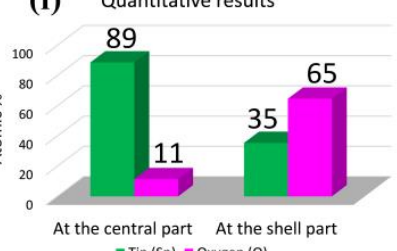

$=\operatorname{Tin}(\mathrm{Sn})=$ Oxygen $(0)$

Figure 5. (a) STEM-HAADF image of a $\mathrm{SnO}_{2} \mathrm{NP}$; (b) EDS spectrum corresponding to the region surrounded by the purple line in (a); (c) STEM-HAADF image of $\mathrm{H}_{2}$-plasma reduced NP after storage in air for one month; (d) EDS spectrum (green solid line) recorded in the shell part of the particle shown in (c) and spectrum (red dashed line) recorded in the central part; (e) Element mapping of Sn (green) and O (pink) in STEM image (c); (f) Chart of quantitative results for Sn (green) and O (pink) in the central and shell parts. Scale bars in (a), (c) and (e) correspond to $50 \mathrm{~nm}$. 
Growth of Si NWs from the reduced metallic Sn droplets. After hydrogen plasma treatment, the distribution of metallic Sn droplets was characterized by SEM. Then, the samples were loaded in the plasma chamber again for NW growth as described in the experimental part. Note that separate reducing and growth steps are not necessary, and can be performed in a single pump-down. Here SEM/ observations were performed in between in order to precisely quantify the number of Si NWs formed per Sn catalyst drops. The Si NWs obtained by plasma-assisted VLS growth from the catalysts particles of Figures 4(d) and 4(f) are shown in Figures 6(a) and 6(b), respectively. Because the growth yield (the number of Si NWs divided by the number of catalyst nanoparticles) is generally small [29], the number of Si NWs formed is much lower than the density of Sn droplets. Nevertheless, the comparison of Figures 6(a) and 6(b) indicates that the final number of Si NWs is proportional to the initial density of catalysts. The ratio of number of NWs to the number of initial $\mathrm{SnO}_{2} \mathrm{NPs}$ is about 2:100.

In previous studies using evaporated Sn, the NW density could be controlled between $2 \times 10^{8}$ $6 \times 10^{8} \mathrm{NW} / \mathrm{cm}^{2}$ [17]. We have prepared many samples with reduced density using the present approach. For instance, the densities of Si NWs are $\sim 2 \times 10^{6} \mathrm{NW} / \mathrm{cm}^{2}$ and $\sim 2 \times 10^{7} \mathrm{NW} / \mathrm{cm}^{2}$ in the two cases shown in Figure 6(a) and 6(b). The use of colloidal solutions of catalyst particles that can be diluted on-demand can thus easily expand the range of Si NWs density down to less than $10^{6} \mathrm{NW} / \mathrm{cm}^{2}$. 


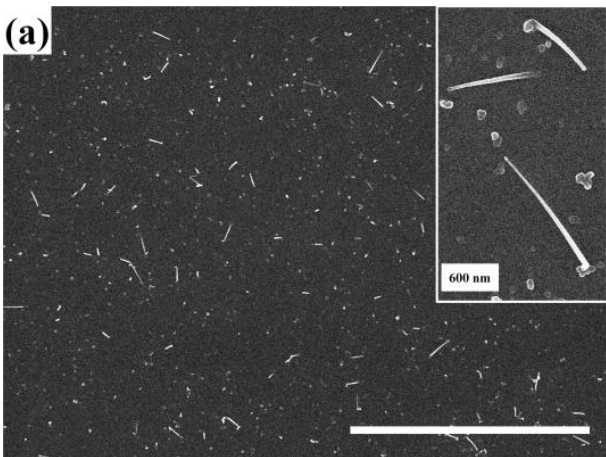

(b)

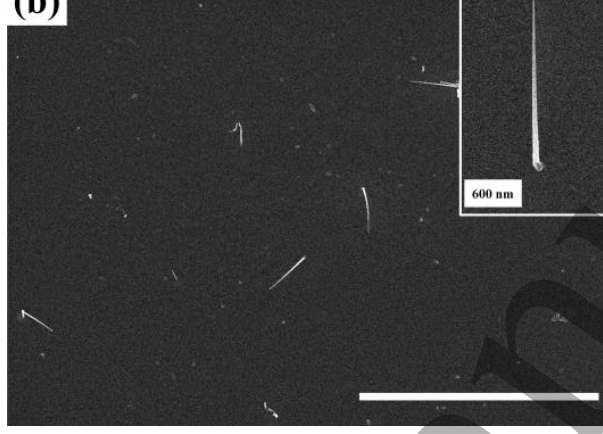

Figure 6. Top view SEM image of Si NWs grown by VLS using reduced Sn droplets acting as catalysts. Si NWs with density (a) $\sim 2 \times 10^{7} \mathrm{NW} / \mathrm{cm}^{2}$ and (b) $\sim 2 \times 10^{6} \mathrm{NW} / \mathrm{cm}^{2}$. Scale bar $10 \mu \mathrm{m}$

Some Si NWs from the sample in Figure 6(a) were transferred to a TEM grid. Figure 7 shows a microstructure for a single NW, with a Sn droplet at the tip and a crystalline structure all along the wire. Fast Fourier Transform (FFT) analyses of selected regions are displayed in Figures 8(b), 9(b) and $9(\mathrm{c})$. They show that the core of the NW is a single crystal, most probably twinned (the pattern is not a standard diamond-cubic silicon pattern). However, there is a clear difference between the FFT patterns in Figure 9(b) and 9(c) taken at spots B-1 and B-2 at the bottom of the NW, which represent the core and shell regions respectively. The core is crystalline while the shell, at that level, is amorphous. 

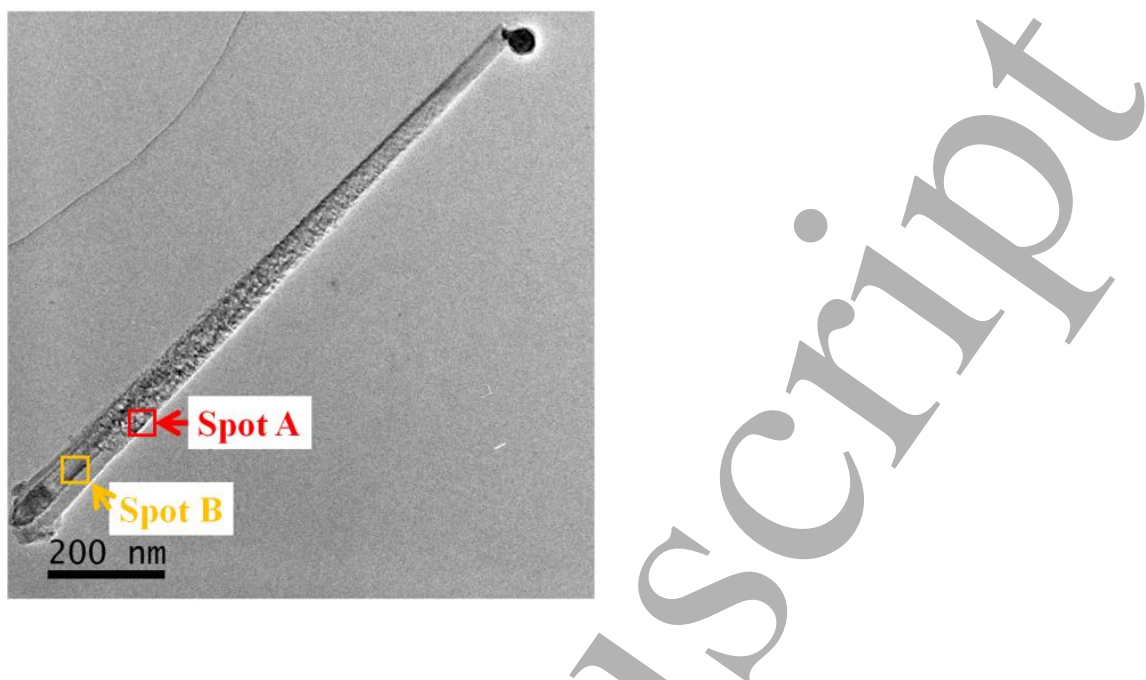

Figure 7. TEM image of one Si NW with a Sn droplet at the tip with two selected regions spot A and spot B.

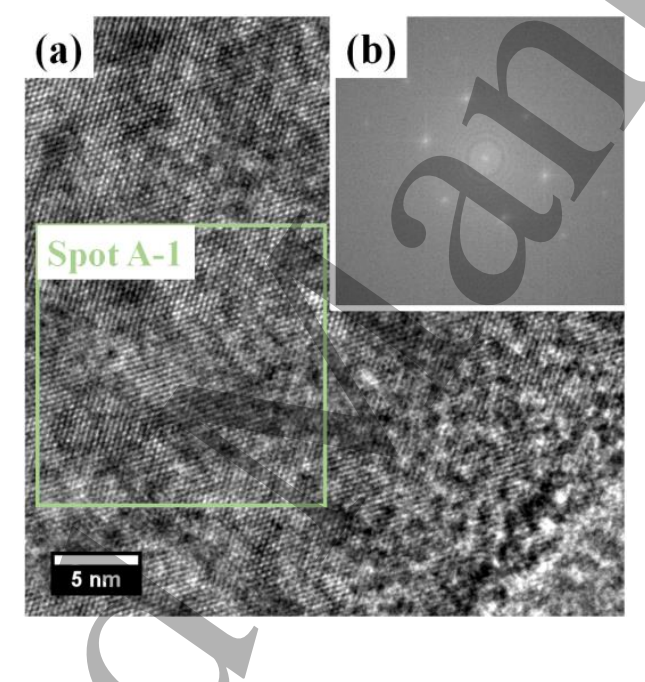

Figure 8. (a) HR-TEM image from spot A (red square) in Figure 7. (b) Fast Fourier Transform of the region into spot A-1 (green square) in (a).

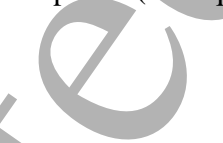



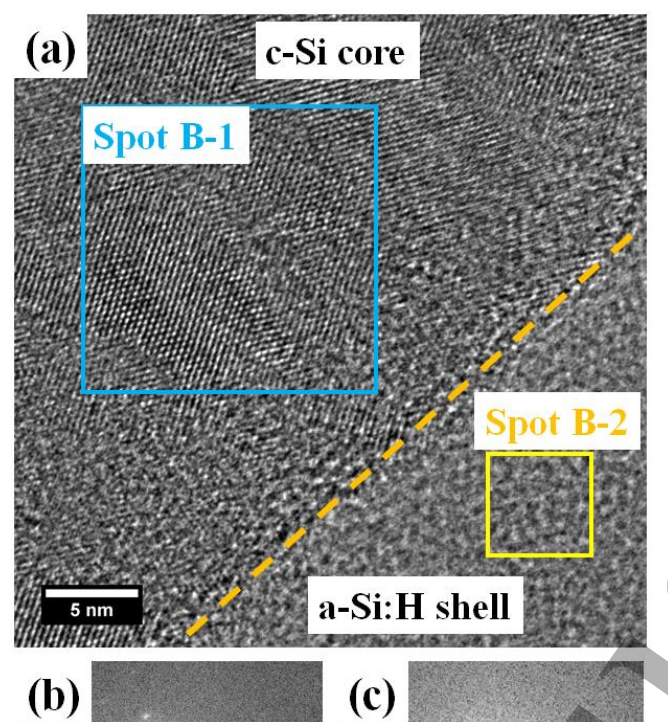

\section{(c)

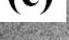

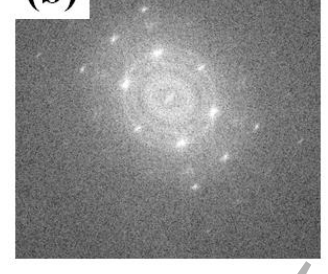

Figure 9. (a) HR-TEM image from spot B (orange square) in Figure 7. Fast Fourier Transform images (b) and (c) of the regions into the spots B-1 (blue square) and B-2 (yellow square) in (a), respectively.

\section{CONCLUSIONS}

This work has shown the potential and versatility of using $\mathrm{SnO}_{2}$ nanoparticles as the source of tin catalyst for the growth of Si NWs. This method allows tuning the density of the catalyst droplets from $10^{9} \mathrm{~cm}^{-2}$ down to at least $10^{7} \mathrm{~cm}^{-2}$ in a reliable and reproducible way. The $\mathrm{SnO}_{2}$ nanoparticles were fully reduced to metallic tin droplets at $400{ }^{\circ} \mathrm{C}$ in a $\mathrm{H}_{2}$ plasma treatment. This allows performing both $\mathrm{SnO}_{2}$ reduction and $\mathrm{Si} \mathrm{NW}$ growth by plasma-assisted VLS in a single pump down process. We have successfully grown crystalline $\mathrm{Si}$ NWs using $\mathrm{Sn}$ reduced from $\mathrm{SnO}_{2} \mathrm{NPs}$ and verified its crystalline structure by TEM. Finally by combining this new approach of using $\mathrm{SnO}_{2} \mathrm{NPs}$ as precursor catalysts and previous results based on Sn thermal evaporation, it is possible to control the density of Si NWs within three orders of magnitudes, from $10^{9}$ down to $10^{6} \mathrm{~cm}^{-2}$. Decreasing the density of grown NWs is necessary for the future development of tandem radial junction devices which involve a larger number of layers, leading to significantly larger diameters. 


\section{ACKNOWLEDGMENT}

This work was financially supported by the project "SOLARIUM" ANR-14-CE05-0025 of the French National Research Agency (ANR). All TEM measurements were performed within the NanoMAX initiative, supported by the project "TEMPOS" ANR-12-BSV1-0029 of the French National Research Agency (ANR). The authors acknowledge H. Arezki for his preliminary work on the stabilization of $\mathrm{SnO}_{2} \mathrm{NPs}$ dispersions.

\section{REFERENCES}

[1] Kayes B M, Atwater H A and Lewis N S 2005 Comparison of the device physics principles of planar and radial p-n junction nanorod solar cells J. Appl. Phys. 97114302

[2] Misra S, Yu L, Foldyna M and Roca i Cabarrocas P 2015 New Approaches to Improve the Performance of Thin-Film Radial Junction, Solar Cells Built Over Silicon Nanowire Arrays IEEE J. Photovoltaics 5 40-5

[3] Wang C, Yu S, Chen W and Sun C 2013 Highly Efficient Light-Trapping Structure Design Inspired By Natural Evolution Sci. Rep. 31025

[4] Foldyna M, Togonal A S, Rusli and Roca iCabarrocas P 2017 Optimization and optical characterization of vertical nanowire arrays for core-shell structure solar cells Sol. Energy Mater. Sol. Cells 159 640-8

[5] Diouf D, Ngo I, Kleider J-P, Gueunier-Farret M and Alvarez J 2012 Nanowire solar cells using hydrogenated amorphous silicon: A modeling study Phys. status solidi 209 1026-30

[6] Qian S, Misra S, Lu J, Yu Z, Yu L, Xu J, Wang J, Xu L, Shi Y, Chen K and Roca i Cabarrocas P 2015 Full potential of radial junction Si thin film solar cells with advanced junction materials and design Appl. Phys. Lett. 10743902

[7] Wagner R S and Ellis W C 1964 VAPOR - LIQUID - SOLID MECHANISM OF SINGLE CRYSTAL GROWTH Appl. Phys. Lett. 489 - 90

[8] Gudiksen M S and Lieber C M 2000 Diameter-Selective Synthesis of Semiconductor 
Nanowires J. Am. Chem. Soc. 122 8801-2

[9] Wang Y, Schmidt V, Senz S and Gösele U 2006 Epitaxial growth of silicon nanowires using an aluminium catalyst Nat. Nanotechnol. 1 186-9

[10] Yu L, Fortuna F, O’Donnell B, Jeon T, Foldyna M, Picardi G and Roca i Cabarrocas P 2012 Bismuth-Catalyzed and Doped Silicon Nanowires for One-Pump-Down Fabrication of Radial Junction Solar Cells Nano Lett. 12 4153-8

[11] Yu L, O’Donnell B, Alet P-J, Conesa-Boj S, Peiró F, Arbiol J and Roca i Cabarrocas P 2009 Plasma-enhanced low temperature growth of silicon nanowires and hierarchical structures by using tin and indium catalysts Nanotechnology 20225604

[12] Yu L, Alet P-J, Picardi G, Maurin I and Roca i Cabarrocas P 2008 Synthesis, morphology and compositional evolution of silicon nanowires directly grown on $\mathrm{SnO}_{2}$ substrates

Nanotechnology 19485605

[13] Tang J, Maurice J-L, Fossard F, Florea I, Chen W, Johnson E V., Foldyna M, Yu L and Roca i Cabarrocas P 2017 Natural occurrence of the diamond hexagonal structure in silicon nanowires grown by a plasma-assisted vapour-liquid-solid method Nanoscale 9 8113-8

[14] Amato M, Kaewmaraya T, Zobelli A, Palummo M and Rurali R 2016 Crystal Phase Effects in Si Nanowire Polytypes and Their Homojunctions Nano Lett. 16 5694-700

[15] Alet P-J, Yu L, Patriarche G, Palacin S and Roca i Cabarrocas P 2008 In situ generation of indium catalysts to grow crystalline silicon nanowires at low temperature on ITO J. Mater. Chem. 185187

[16] Yu L, O’Donnell B, Foldyna M and Roca i Cabarrocas P 2012 Radial junction amorphous silicon solar cells on PECVD-grown silicon nanowires Nanotechnology 23194011

[17] Misra S, Yu L, Foldyna M and Roca i Cabarrocas P 2013 High efficiency and stable hydrogenated amorphous silicon radial junction solar cells built on VLS-grown silicon nanowires Sol. Energy Mater. Sol. Cells 118 90-5

[18] Suematsu K, Shin Y, Hua Z, Yoshida K, Yuasa M, Kida T and Shimanoe K 2014 Nanoparticle 
cluster gas sensor: Controlled clustering of $\mathrm{SnO} 2$ nanoparticles for highly sensitive toluene detection ACS Appl. Mater. Interfaces 6 5319-26

[19] Leite E R, Giraldi T R, Pontes F M, Longo E, Beltrán A and Andrés J 2003 Crystal growth in colloidal tin oxide nanocrystals induced by coalescence at room temperature Appl. Phys. Lett. $831566-8$

[20] Girard H A, Perruchas S, Gesset C, Chaigneau M, Vieille L, Arnault J C, Bergonzo P, Boilot J P and Gacoin T 2009 Electrostatic Grafting of Diamond Nanoparticles: A Versatile Route to Nanocrystalline Diamond Thin Films ACS Appl. Mater. Interfaces $12738-46$

[21] Kim J, Dantelle G, Revaux A, Bérard M, Huignard A, Gacoin T and Boilot J-P 2010 PlasmonInduced Modification of Fluorescent Thin Film Emission Nearby Gold Nanoparticle Monolayers Langmuir 26 8842-9

[22] Sabat K C, Rajput P, Paramguru R K, Bhoi B and Mishra B K 2014 Reduction of Oxide Minerals by Hydrogen Plasma: An Overview Plasma Chem. Plasma Process. 34 1-23

[23] Rasband, W.S., ImageJ, U. S. National Institutes of Health, Bethesda, Maryland, USA, https://imagej.nih.gov/ij/, 1997-2016.

[24] Gohin M, Allain E, Chemin N, Maurin I, Gacoin T and Boilot J P 2010 Sol-gel nanoparticulate mesoporous films with enhanced self-cleaning properties J. Photochem. Photobiol. A Chem. $216142-8$

[25] Kosmulski M 2009 Compilation of PZC and IEP of sparingly soluble metal oxides and hydroxides from literature Adv. Colloid Interface Sci. 152 14-25

[26] Zhan S, Li D, Liang S, Chen X and Li X 2013 A novel flexible room temperature ethanol gas sensor based on $\mathrm{SnO}_{2}$ doped poly-diallyldimethylammonium chloride Sensors (Switzerland) 13 $4378-89$

[27] Kim B-S, Lee J-C, Yoon H-S and Kim S-K 2011 Reduction of $\mathrm{SnO}_{2}$ with Hydrogen Mater. Trans. 52 1814-7

[28] Wallinga J, Arnoldbik W M, Vredenberg a M, Schropp R E I and Van Der Weg W F 1998 
Reduction of Tin Oxide by Hydrogen Radicals J. Phys. Chem. B 102 6219-24

[29] Tang J, Maurice J-L, Chen W, Misra S, Foldyna M, Johnson E V. and Roca i Cabarrocas P 2016 Plasma-Assisted Growth of Silicon Nanowires by Sn Catalyst: Step-by-Step Observation Nanoscale Res. Lett. 11455 